Douglas Fisher and Adrian Fleissig

Douglas Fisher is professor of economics at North Carolina State University. Adrian Fleissig is assistant professor of economics at the University of Texas-Arlington. The authors wish to acknowledge the assistance of Ron Gallant, Douglas Pearce, Walter Thurman and Michael Belongia, who made im. portant suggestions for the revision of this paper.

\title{
Money Demand in a Flexible Dynamic Fourier Expenditure
} System

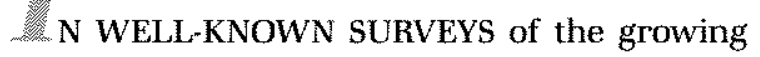
literature on expenditure systems, Deaton and Muellbauer (1980) and Pollak and Wales (1992) describe many of the shortcomings of the existing work in this genre. Among the problems they list that inhibit the acceptance of these methods, the ones that seem most critical to us are (1) the failure to link theory to application, (2) improper aggregation techniques, (3) imprecise estimation of partial derivatives, (4) the failure of locally integrable models at some data points and (5) the misspecification of the dynamics. We can address several of these problems by extending the Fourier Flexible Form of Gallant (1981). Most notably, his technique provides global flexibility and arbitrarily accurate estimates of partial derivatives. In fact, the technique is capable of approximating the unknown function (an aggregator function, for example) to any desired degree of accuracy. The version of the Fourier model in current use, however, is static in nature, which inhibits its application to timeseries data; in particular, studies by Gallant (1981), Ewis and Fisher (1985), and Fisher (1989, 1992), all employ the static model and all produce residuals that are not white noise for each share; see also Barnett, Fisher, and Serletis (1992). This may be due to inadequately modeled dynamics; in fact, there are no examples of a dynamic Fourier in the literature. The task of this paper is to produce and evaluate two dynamic alternatives in the context of the Fourier model.

In the traditional literature on consumer choice, the indirect utility function is approximated by a specific functional form in order to obtain expenditure shares and estimates of the important own- and cross-elasticities. One might attempt to estimate a parametric model, of course, but the results of such exercises have not been satisfactory. The chief problem has been model failure, partly related to the choice of specific (nonflexible) functional forms. To finesse this problem, a flexible functional form can be employed in order to estimate the unknown indirect utility function. Diewert (1974) defines a flexible functional form as a secondorder approximation to an arbitrary twice continuousy differentiable function $f(x)$ at any given point $x^{*}$; the popular translog is an example. 'The difficulty, however, is that this definition, and the resulting approximation, fails to impose precision on the partial derivatives of the function. Indeed, it is well-known that away from the point of approximation, the translog can perform quite poorly in its task of tracking the unknown function. The result is imprecise estimation of the expenditure shares. 
Gallant (1981) developed the Fourier flexible form in order to approximate the unknown indirect utility function and its first derivatives arbitrarily accurately within a Sobolov norm. The first derivatives are important since the expenditure shares are derived by differentiation. The Fourier model, with its global properties, can then provide integrability over a finite region for the estimated model, assuming convergence. In particular, since integrability nor. mally implies a convex closure over a finite region, one can presume desirable separability properties for data examined under the Sobolov norm. This contrasts, as noted, with the possible lack of closure on procedures that provide an approximation only at a single point in the data space; in particular, it contrasts with locally integrable models (such as the Translog).

In this paper, we produce two versions of the dynamic Fourier expenditure system; these are then compared with the static model in various ways. In section two we briefly discuss the static model before going into considerable detail over what we will be calling the "timeseries approach" to making the fourier model dynamic. This basically follows the lead of Anderson and Blundell $(1982,1983)$, whose results are both well-known and have been applied in the literature on flexible functional forms (see Serletis, 1991). In section three, we continue with a second version of the dynamics, this time involving the construction of the dynamic Fourier utility function. We term this the "dynamic utility function approach." In section four, we present examples of the two dynamic models in order to clarify the ideas and explain the notation. It is here possible to establish clear distinctions between the models in the context of the Fourier. In section five, we go over the procedures used to prepare the data, and in section six, finally, we discuss estimates of the two dynamic models that utilize the U.S. data previously described. We also discuss how the two models perform in comparison with their static equivalents. Our conclusions follow.

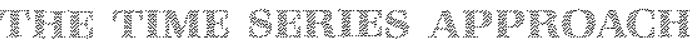

Following Gallant (1981), the static Fourier flex" ible form approximation of an indirect utility function $h(v)$ may be written as

(1) $h_{k}(v \theta)=a_{d j}+b^{\prime} v+\frac{1}{2} v^{\prime} C v+\sum_{\alpha=1}^{A} \sum_{j=-J}^{J} a_{j a} e^{i j k^{\prime} v^{\prime}}$

where

$C=-\sum_{\alpha=1}^{A} a_{a \alpha} k_{\alpha} k_{a}^{\prime}$ and $a_{j a}=\bar{a}_{-j \alpha}$.

$a_{v^{\prime}} \mathbf{a}_{a b}$ and $b$ are real-valued, and $\mathbf{v}$ is a vector of the expenditure-normalized user costs of the particular assets involved in the exercise (Gallant, 1981). In this expression the overbar denotes complex conjugation and $i$ is the imaginary number. A multi-index $k_{\mathrm{a}}$, is an $n$-vector with integer components and is used to denote partial differentiation of the utility function (see the example in section four). The elements of a multiindex can be considered to be the weights when multiplied by $v$ ) of the normalized price indexes.

In an empirical investigation, it is actually more convenient to work with a sine/cosine formulation rather than the exponential just written and so the following form is generally employed:

$$
\begin{aligned}
& \text { (2) } h_{k}(v, \theta)=u_{o}+b^{\prime} v+\frac{1}{2} v^{\prime} C v \\
& +\sum_{\alpha=1}^{\mathrm{A}}\left|u_{o \alpha}+2 \sum_{j=1}^{\mathrm{J}}\left[u_{j a} \cos \left(j k_{\alpha}^{\prime} v\right)-w_{j a} \sin \left(j k_{\alpha}^{\prime} v\right)\right]\right|
\end{aligned}
$$

in which

$$
C=-\sum_{\alpha=1}^{\mathrm{A}} u_{\mathrm{j}, \alpha} k_{\alpha} k_{\alpha}^{\prime} .
$$

After differentiating equation 2 and applying Roy's identity, Gallant arrives at the following set of equations:

$$
\frac{v b_{i}-\sum_{\alpha=1}^{A}\left(u_{o \alpha} v^{\prime} k_{\alpha}+2 \sum_{j=1}^{J} j\left[u_{j \alpha} \sin \left(j k_{\alpha}^{\prime} v\right)+w_{j \alpha} \cos \left(j k_{\alpha}^{\prime} v\right)\right]\right) k_{i \alpha} v_{i}}{b^{\prime} v-\sum_{\alpha=1}^{A}\left(u_{u \alpha} v^{\prime} k_{\alpha}+2 \sum_{j=1}^{J} j\left[u_{j \alpha} \sin \left(j k_{\alpha}^{\prime} v\right)+w_{j \alpha} \cos \left(j k_{\alpha}^{\prime} v\right)\right]\right) k_{\alpha} v},
$$


for $i=1, \ldots, n$ expenditure shares. This system is what is estimated with a vector of error terms appended. Equation (3) can be more compactly expressed as:

(4) $y_{i t}=f\left(v_{t^{\prime}}, \theta\right)$.

Note that we have attached a time subscript in order to emphasize the static nature of the equations. This completes the discussion of the static Fourier Flexible model.

Consumption, monetary and production theories use past variables-in the utility function, in the constraints, or by time-series methodsto model habit persistence, adjustment costs and/or expectations. In a demand systems approach, incorporating dynamics in any of these ways complicates the calculation of the restrictions, which still must hold. In the following exercises we present results for the time-series function and, in section three, for the utility function. We present the models first including with each a discussion of the restrictions, before presenting examples of both.

For the time series model, applying an ARMA $(p, q)$ directly to equation (4) is one approach toward modeling the dynamic behavior of the consumer. This approach is taken by Anderson (1980) for the special case when $f\left(v_{1}, \theta\right)$ is linear in the expenditure-normalized prices $v_{t}$ and the parameters $\theta$. He shows that adding up, as the direct result of adopting the ARMA approach, implies four additional restrictions. Anderson and Blundell $(1982,1983)$ extend the results for the case in which $f\left(v_{t}, \theta\right)$ may be nonlinear in the parameters but linear in the normalized prices $V$, i.e., $f\left(v_{t}, \theta\right)=\pi(\theta) v_{t}$. When applying an ARMA $(p, q)$ to equation (4), they can extract a term, $y_{t p p}$ $\pi(\theta) v_{r-q}$, the gap between the shares lagged $\mathrm{p}$ periods and normalized prices lagged $\mathrm{q}$ periods, representing the long-run structure for a system of simultaneous equations. This approach is not applicable when the matrix $\pi(\theta)$ cannot be extracted, as is the case with the Fourier flexible functional form; as a consequence, we use an alternative approach for analyzing the long-run structure. First, an ARMA(p,q) is applied to equation (4). The result is:

(5) $A(L) y_{t}=B(L) f\left(v_{t}, \theta\right)$.

Here, where $\mathrm{L}$ is the lag operator, the terms $A(L)$ and $B(L)$ represent the following distributed lags

$$
\begin{aligned}
& A(L)=I+A_{1} L+A_{2} L^{2}+\ldots+A_{p} L^{p} \\
& B(L)=I+B_{1} L+B_{2} L^{2}+\ldots+B_{q} L^{q} .
\end{aligned}
$$

Consider the following ARMA(1,1):

(6) $y_{t}=A_{1}^{*} y_{t, t}+f\left(v_{z^{\prime}} \theta\right)+B_{1}^{*} f\left(v_{t-y^{\prime}} \theta\right)+e_{i}$.

As in Anderson and Blundell $(1982,1983)$, the addingup restrictions require a transformation $A_{1}^{*}$ of $A_{1}$ where the columns of $A_{1}^{*}$ must sum to zero, and $a_{i j}{ }^{*}=a_{i j}-a_{i n}$ for $i=1, \ldots, n$ and $j=1, \ldots, n-1$. Similar restrictions for the matrix $B_{1}^{*}$ apply. In sum, then, the dynamics appear as lagged shares $y_{t \cdot l}$ and lagged normalized prices $v_{t-i^{\circ}}$

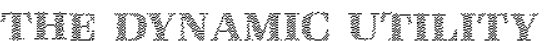 WUEV}

Individuals are unlikely, generally, to be able to adjust their consumption plans instantaneously. Rather than apply an arbitrary lag to the shares derived from a static optimization exer. cise, an attractive alternative is to allow past behavior to affect current decisions directly through the utility function. We can define the set of past decisions on a commodity to be an nxt vector of shares $(\boldsymbol{s})$ that are functions of all past values of $\mathrm{v}$ :

(7) $s=f\left(v_{t, r}\right)$ for $r=1, \ldots, n-1$.

Here, each share depends on its own lagged normalized price and the lagged normalized prices of the remaining $n-1$ shares. In this case, the representative consumer's dynamic indirect utility function can be expressed as

(8) $U=U(v, s)$,

where $v=P / M$ and $s$ represents the dynamics. $M$ is total "expenditures" on this class of assets. This is, in effect, a structural approach for obtaining dynamic shares since the dynamics are embedded in the decision process rather than appearing as dynamic extensions of the static shares (as in the time-series model). It produces a new version of the Fourier model, accordingly. To begin with, we will let $s=x_{t-1}$, so that each share depends on its own lagged value as well as on lags from the remaining $n-1$ shares. 
The dynamic Fourier Flexible Form is defined as

(9) $g_{k}^{d}(z, \theta)=u_{\sigma}+b^{\prime} z+\frac{1}{2} z^{\prime} C z+\sum_{\alpha=1}^{A} \sum_{j=-J}^{J} a_{j \alpha} e^{j i k^{\prime} z^{z}}$

and

$C=-\sum_{\alpha=1}^{A} u_{a \mathrm{a}} K_{\alpha} K_{\alpha}^{\prime} \quad z=\left(\begin{array}{c}v^{\prime}{ }^{\prime} \\ v_{t-1}^{\prime}\end{array}\right)$.

Parallel to equation 2, we may express the model as

(10)

$$
\begin{aligned}
& g_{k}^{d}(z, \theta)=u_{o}+b^{\prime} z+\frac{1}{2} z^{\prime} C z \\
& +\sum_{\alpha=1}^{A}\left(u_{o \alpha}+2 \sum_{j=1}^{J}\left(u_{j \alpha} \cos \left(j k_{\alpha}^{\prime} z\right)-w_{j \alpha} \sin \left(j k_{\alpha}^{\prime} z\right)\right]\right)
\end{aligned}
$$

in which

$$
C=-\sum_{\alpha=1}^{A} u_{v \mathrm{u}} K_{\mathrm{a}} K_{\alpha}^{\prime}
$$

In this formulation, a multi-index is now a 1 by $(r+1)(n)$ vector with integer components; in the static case, it was 1 by $(n)$. Here, $r$ is the number of lags. The dynamic shares for this problem are obtained by applying Roy's identity to equation 10:

$$
\frac{v_{i t} b_{i}-\sum_{\alpha=1}^{A}\left(u_{o \alpha} z^{\prime} k_{\alpha}+2 \sum_{j=1}^{J} j\left[u_{j \alpha} \sin \left(j k_{\alpha}^{\prime} z\right)+w_{j \alpha} \cos \left(j k_{\alpha}^{\prime} z\right)\right]\right) k_{i \alpha} z_{i}}{\sum_{i=1}^{n} b_{i} v_{i t}-\sum_{\alpha=1}^{A}\left(u_{o \alpha} z^{\prime} k_{\alpha}+2 \sum_{j=1}^{J} j\left[u_{j \alpha} \sin \left(j k_{\alpha}^{\prime} z\right)+w_{j \alpha} \cos \left(j k_{\alpha}^{\prime} z\right)\right]\right) k_{\alpha}^{\prime} z},
$$

where $i=1, \ldots, n$. This can be more compactly expressed as

$$
y_{t}=f\left(v_{t}, v_{t-1}, \theta\right)
$$

In this model, adding up is guaranteed, and no additional restrictions need to be applied at the estimation stage.

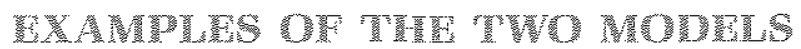

In the two models just presented, the dynamics are captured in quile different ways. For the time-series approach, the dynamics enter in the form of lagged shares and lagged expenditure- normalized prices. In the dynamic utility function model, the dynamics enter only as lagged normalized prices in each of the share equations. The dynamic models can be more clearly compared with an example, which is what we now present. Note that we use what are termed "multi-indices" in the process of estimating the Fourier model. This is a notational convenience, as we have explained, for expressing the partial differentiation of the indirect utility function and can be considered as weights (linear combinations $k \alpha^{\prime} v$ ) of normalized prices.

In this example we will be looking at four share equations, with $A=4$ and $J=1$ in the Fourier model. The multi-indices used for the timeseries approach, assuming an ARMA(1,0), are:

$k_{\mathrm{a}}=\left(\begin{array}{l}k_{\mathrm{xa}} \\ k_{2 \mathrm{k}} \\ k_{3 \mathrm{a}} \\ k_{4 \mathrm{a}}\end{array}\right)$ where $k_{1}=\left(\begin{array}{l}0 \\ 0 \\ 1 \\ 1\end{array}\right), k_{2}=\left(\begin{array}{l}1 \\ 0 \\ 1 \\ 0\end{array}\right)$,

$k_{3}=\left(\begin{array}{l}0 \\ 1 \\ 0 \\ 1\end{array}\right), k_{4}=\left(\begin{array}{l}1 \\ 1 \\ 1 \\ 0\end{array}\right)$ with $V=\left(\begin{array}{l}V_{11} \\ V_{2 t} \\ V_{3 t} \\ V_{4 t}\end{array}\right)$
Note that $V$ defines the four expenditurenormalized prices. The multi-indices are set up in the same way as in Gallant (1981) and one must be careful, when taking partial derivatives, to ensure that the corresponding $k_{i x}$ is used. In this example, the first element of each of the multi-indices, zero or one, corresponds to the first element in $V$; this is the nornalized price, $V_{1}$. Since the dynamics are modeled by adding lagged expenditure shares, the dimension of the multi-indices, which only appears in $f\left(v_{t}, \theta\right)$ in equation 5 , stays the same when one moves from the static to the dynamic time series model. 
On the other hand, in the dynamic utility approach, the inclusion of lagged normalized prices increases the length of each multi-index [see $f\left(v_{p}, v_{t, k}, \theta\right)$ in equation 12]; we use the following eight indices, accordingly:

$k_{1}=\left|\begin{array}{c}1 \\ 0 \\ 1 \\ 0 \\ 0 \\ 0 \\ 0 \\ 0 \\ 0\end{array}\right|, k_{2}=\left|\begin{array}{c}0 \\ 1 \\ 1 \\ 0 \\ 0 \\ 0 \\ 0 \\ 0 \\ 0\end{array}\right|, k_{i 3}=\left|\begin{array}{c}1 \\ 0 \\ 1 \\ 1 \\ 0 \\ 0 \\ 0 \\ 0 \\ 0\end{array}\right|, k_{4}=\left|\begin{array}{c}0 \\ 0 \\ 0 \\ 1 \\ 0 \\ 0 \\ 0 \\ 0\end{array}\right|$

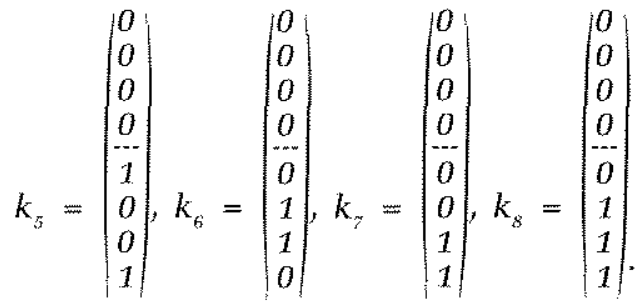

In this case the vector of normalized prices is

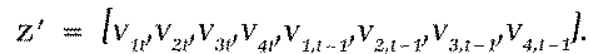

The first four elements of each $k_{\alpha}$ correspond to the static part of the vector $z$ and the last four elements of each $k_{\mathrm{a} z}$ to the dynamic elements of $z$. This separation of multi-indices enables one to test the static against the dynamic utility function because each multi-index has an associated parameter.

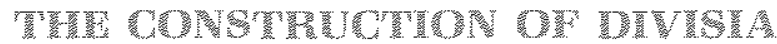

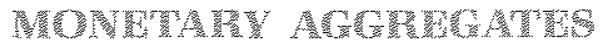

Most of the studies of money demand in the literature employ monetary aggregates that are simple sums of their components (for example; $M 1=$ Currency plus deposits) and are constructed essentially without benefit of index-number the ory. While simple-sum aggregation might serve policy makers well when interest rate fluctuations are relatively mild, it is at a disadvantage when the relative interest rates on the monetary components fluctuate significantly. A Divisia index is an alternative approach for aggregating data that is based directly on economic theory. The Divisia index, indeed, is designed to internalize the substitution effects (at constant utility) that arise from relative price changes. In fact, the simple-sum index cannot produce this result unless the components of the proposed aggregation are perfect substitutes. We have reason to believe this is not the case for the monetary aggregates in common use.

Having a satisfactory procedure such as the Divisia does not, however, tell us exactly what set of assets to consider or how to group the subsets of the data for efficient estimation. A procedure that is available is the linear NONPAR program of Varian $(1982,1983)$, which is based directly on the Generalized Axiom of Revealed Preference (GARP). Satisfaction of GARP on a set of data implies that there exists a non-satiated, concave, monotonic utility function across that particular set. Such a set of data, if it exists, can be examined for logical groupings, again using the program NONPAR. If such groupings can be established - that is, if weak separability holdsthen, according to the Leontief-Sono definition of separability, the marginal rates of substitution between any two commodities in the monetary index are independent of changes in relative prices outside the monetary group. This group is then available for (Divisia) aggregation.

On the quarterly U.S. data from 1970:1 to 1985:2, Swofford and Whitney (1987) have constructed a set of real per capita measures of monetary quantities and a set of related nominal user costs to represent the prices of these quantities. With M1 denoting narrow money (excluding the deposits of businesses); OCD, other checkable deposits; SD, savings deposits in financial institutions; and STD, small time deposits in financial institutions, they find that the following arrangement passes the necessary and sufficient conditions for the General Axiom of Revealed Preference:

UIV(DUR, NONDUR, SERV, LEIS), M1, OCD, SD, STDI.

Here, the first three items in the equation refer to components of total consumption, while LEIS refers to leisure (evaluated at the wage rate). Note that SD and STD describe vectors of the liabilities of the various financial institutions (for example, $S D=$ small time deposits in com- 
mercial banks, S\&Ls, and so on/1. Also, notice that in the arrangement just listed, the consumption and leisure activities are separable from the financial assets but not the converse. This implies the existence of an aggregate utility function defined across these monetary entities (for this time and place).

Because of the failure to establish a subgrouping of the monetary assets, it proves necessary to work with the following four aggregate commodities:

$M 1, O C D$

SDCB, SDSL, SDSB, SDCU

A2

STDCB, STDTH, STDCU

A3

DUR, NONDUR, SERV, LEIS.

Here, SDCB and so on are savings deposits at commercial banks, S\&Ls, mutual savings banks and credit unions, while STDCB and so on are small time deposits at commercial banks, thrifts and credit unions. To attempt to preserve the economic characteristics of this set of data up to a third-order remainder term, Divisia index numbers are constructed from the individual quantities and their associated user costs; these are designated as A1, .., A4. Note that $\mathrm{M} 1$ and OCD are summed for convenience; this can be justified by further noting that the correlation coefficient between the user costs of these two items is .994.

Putting all the pieces together, then, we have monetary data (and user costs) that satisfy an empirical test for revealed preference, we have aggregated the data in a way that is designed to preserve their economic characteristics in the face of changes in relative prices and, finally, we propose to estimate the elasticities using a model which can come arbitrarily close to the elasticities implied by the true (but unknown) aggregate indirect utility function known to be defined (by the GARP test) over these entities. Note, especially, that satisfaction of GARP implies that there is a firm link between the in-

\footnotetext{
The original variables were supplied by the Federat Reserve and appear in several publications by Farr and Johnson (1985a, 1985b). In this study, the monetary data are employed in per capita real form (where the latter is achieved by deflation with the CPI). SD represents savings deposits in commercial banks, S\&Ls, mutual savings banks and credit unions, while STD represents the small time deposits of the same institutions. $O C D$ is other checkable deposits and includes NOW accounts. See Swofford and Whitney's two papers for mole details on the construction of the data.

As discussed in Swofford and Whitney $(1987,1988)$, the
}

direct utility that is actually estimated and the underlying utility function that actually gener. ates these data.

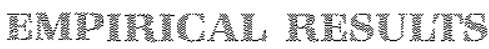

In our empirical work, we compare the results of the estimation of the three systems: the stat ic, the time series dynamic and the utility fun. ction dynamic. Because the static theory is nested in each of the two dynamic theories, we present the results in that form. The comparisons are in terms of the significance of the coefficients, the characteristics of the residuals and the relevance of the dynamic formulations using the results of the Gallant-Jorgenson (1979) chi-square test. Unfortunately, the two dynamic approaches are not nested, so that we cannot compute a Gallant-Jorgenson test statistic. We do, however, offer a comparison utilizing the other statistics just mentioned. As it turns out, neither model has a clear advantage, although we do prefer the dynamic utility model in view of its economic properties and adequate performance. We also offer some comparisons with earlier work that utilized the static Fourier model over the same data space (Fisher, 1992). Here, there are dramatic differences in the estimated elasticities of substitution; we believe the dynamic results futilizing the estimates from the dynamic utility approach) are considerably more reasonable than the earlier static results.

The share equations, with the across-equations restrictions, were estimated in the SAS system using PROC MODEL with nonlinear seemingly unrelated regression. The results for the dynamic time-series model appear in Table 1.

In this table, the $B s$ correspond to the quadratic terms in the Fourier Flexible Form, the $U s$ and $V s$ to the Fourier series expansion, and the As to the lagged shares $y_{t-x^{*}}$

These results describe reasonable fits, with 10 of the 12 adjustment parameters $\left(A_{i j}\right)$ having $t$ - data were prepared as follows. Each monetary asset is deflated by the consumer price index for urban areas. OCD includes super NOW accounts. The user cost is the concept defined by Barnett (1978). For leisure, the quantity is 98 hours less average weekly hours worked during the quarter (times 52). The wage rate measures the opportunity cost of time. The consumption figures are taken from Department of Commerce data that also provides the implicit deflator for each category. A 10 percent depreciation rate is used in calculating the one-period holding cost of a durable good. 
Table 1

Time Series Model: Dynamic Fourier Flexible Functional Form

\begin{tabular}{|c|c|c|c|c|c|c|c|}
\hline \multicolumn{8}{|c|}{ Nonilinear SUA summary of residual errors: } \\
\hline Eqn. & model & of & SSE & MSE & $\begin{array}{l}\text { Root } \\
\text { MSE }\end{array}$ & $\begin{array}{l}R \\
\text { square }\end{array}$ & $\begin{array}{l}\text { Adjust } \\
\text { A-square }\end{array}$ \\
\hline SM1 & 9 & 53 & 0.00438 & 0.0000827 & 0.00909 & 0.915 & 0.902 \\
\hline SM2 & 9 & 53 & 0.01650 & 0,0003113 & 0.01764 & 0.848 & 0.825 \\
\hline SM3 & 9 & 53 & 0.02445 & 0.0004613 & 0.02148 & 0.923 & 0.912 \\
\hline
\end{tabular}

Nonlinear SUR parameter estimates

\begin{tabular}{|c|c|c|c|c|}
\hline Parameter & Estimate & $\begin{array}{c}\text { Approximate standard } \\
\text { error }\end{array}$ & "T" Ratio & $\begin{array}{c}\text { Approximate } \\
\text { prob }>|T|\end{array}$ \\
\hline B1: & 0.175462 & 0.08184 & 2.14 & 0.0367 \\
\hline $\mathrm{B} 2$ & 00007578 & 0.25542 & 0.03 & 0.9764 \\
\hline B3 & $-0,448512$ & 0.15285 & 2.93 & 0.0049 \\
\hline U01. & -0.007955 & 0,02828 & 0.28 & 0.7796 \\
\hline U11: & -0.009762 & 0.00710 & 1.37 & 0.1752 \\
\hline W11 & 0.023864 & 0.02545 & 0.94 & 0.3526 \\
\hline A11 & 0,419255 & 0.07229 & 5.80 & 0.0001 \\
\hline A12: & 0.259178 & 0.03873 & 6.69 & 0.0001 \\
\hline A13 & 0.197632 & 0.02071 & 9.54 & 0.0001 \\
\hline A14 & 0.190888 & 0.04239 & 4.50 & 0.0001 \\
\hline U02 & -0.014187 & 0.01355 & 1.05 & 0.3000 \\
\hline U12 & 0.011554 & 0.01015 & 1.14 & 0.2599 \\
\hline W12 & -0.019444 & 0.00809 & 2.40 & 0.0197 \\
\hline A21 & -1.000371 & 0.13602 & 7.35 & 0.0001 \\
\hline $\mathrm{A} 22$ & 0.958742 & 0.06774 & 14.15 & 0.0001 \\
\hline A23 & -0.034480 & 0.03080 & 1.12 & 0.2680 \\
\hline $\mathrm{A} 24$ & 0.766254 & 0.08967 & 8.55 & 0.0001 \\
\hline Uos & 0.020581 & 0.00692 & 2.97 & 0.0044 \\
\hline U13 & -0.002235 & 0.00216 & 1.03 & 0.3062 \\
\hline W13 & 0.002259 & 0.00146 & 1.55 & 0.1272 \\
\hline $\mathrm{A} 31$ & 0.572904 & 0.11232 & 5.10 & 0.0001 \\
\hline $\mathrm{A} 32$ & -0.381781 & 0.07622 & 5.01 & 0.0001 \\
\hline $\mathrm{A} 33$ & 0.276142 & 0,04249 & 6.50 & 0.0001 \\
\hline $\mathrm{A3} 4$ & -0.119175 & 0.08974 & 1.33 & 0.1899 \\
\hline U04 & -0.009973 & 0.00554 & 1.80 & 0.0778 \\
\hline U14 & -0.000714 & 0.00236 & 0.30 & 0.7638 \\
\hline W14 & 0.000171 & 0,00287 & 0.06 & 0.9527 \\
\hline
\end{tabular}

$N=62$

Objective $=2.0164$

Objective $N=125.0495$

The Aif represent the dynamics.

values in excess of 2 . Note that it is the surfaces of $(\partial / \partial x) g^{*}(x)$ and $\left(\partial^{2} / \partial x \partial x^{\prime}\right) g^{*}(x)$ that one aims to estimate accurately; it is not required that all parameters be significant. The coefficients capturing the dynamics tend to be the most significant parameters. We also calculated the autocorrelation and partial autocorrelations for each of the three share equations; the residuals here were white noise. In order to compare the dynamic and static results, we apply the Gallant-Jorgenson chi-square test to provide a comparison with the static equivalent of the time series model. The test statistic uses the value "objective* $N$ " in the table. For the static model the estimates are not shown here), the value of this statistic is 527.9597 ; for the dynamic it is 125.0495 as shown in the table. The value of the Gallant.Jorgenson statistic is then $527.9597-125.0495=402.9102$ with degrees of freedom equal to the difference in the number of parameters, of $27-15=12$. This calculation decisively rejects the static model. 
Table 2

Utility Function Model: Dynamic Fourier Flexible Functional Form

\begin{tabular}{|c|c|c|c|c|c|c|c|}
\hline \multirow[b]{2}{*}{ Eqn. } & \multicolumn{6}{|c|}{ Nonlinear SUR summary of residual errors } & \multirow[b]{2}{*}{$\begin{array}{l}\text { Adjust } \\
R \text {-square }\end{array}$} \\
\hline & MF & $\begin{array}{l}\text { DF } \\
\text { Error }\end{array}$ & SSE: & MSE & $\begin{array}{l}\text { Root } \\
\text { MSE }\end{array}$ & $\begin{array}{l}R- \\
\text { Square }\end{array}$ & \\
\hline SM1. & 9 & 53 & 0.01057 & 0,0001995 & 001412 & 0.796 & 0.765 \\
\hline SM2 & 9 & 53 & 0.01885 & 00003556 & 0.01886 & 0.826 & 0.800 \\
\hline $\mathrm{SM}_{3}$ & 9 & 53 & 0.03803 & 0.0007175 & 0.02679 & 0.880 & 0.862 \\
\hline
\end{tabular}

Nonlinear SUR parameter estimates

\begin{tabular}{|c|c|c|c|c|}
\hline Parameter & Estimate & $\begin{array}{c}\text { Approximate standard } \\
\text { error }\end{array}$ & "T ratio & $\begin{array}{c}\text { Approximate } \\
\text { prob }>|T|\end{array}$ \\
\hline Bt. & -0.163039 & 0.38557 & 0.42 & 0.6741 \\
\hline B2: & -1.187580 & 0.32865 & 3.61 & 0.0007 \\
\hline $\mathrm{B3}$ & -1.028066 & 0.35163 & 2.92 & 0.0051 \\
\hline Uot & 0016757 & 003275 & 0.51 & 0.6110 \\
\hline U1t: & -0.002319 & 001498 & 0.15 & 0.8776 \\
\hline Wit & 0.027816 & 0.02235 & 1.24 & 0.2187 \\
\hline บos & 0.002500 & 002955 & 0.08 & 09329 \\
\hline U15: & 0.009921 & 001450 & 068 & 0.4968 \\
\hline W15 & -0.064331 & 0.03009 & 2.14 & 0.0372 \\
\hline U02 & -0.111290 & 003773 & 2.95 & 0.0047 \\
\hline U12: & 0061322 & 0.01864 & 3.29 & 0.0018 \\
\hline W12 & 0022699 & 0.01756 & 1.29 & 0.2023 \\
\hline 406 & -0.008559 & 0.01160 & 0.74 & 0.4637 \\
\hline U16: & 0.006524 & 0.00869 & 0.75 & 0.4561 \\
\hline W16 & $\therefore 0.001616$ & 0.00993 & 0.16 & 0.8713 \\
\hline Uos & -0.006461 & 0.01692 & 0.38 & 0,7041 \\
\hline U13 & 0006416 & 0.01338 & 0.48 & 0.6335 \\
\hline W13 & -0.113939 & 0.00800 & 1.42 & 0.1604 \\
\hline U07: & -0.013340 & 0.01127 & 1.18 & 0.2419 \\
\hline U17 & 0000898 & 0.00873 & 0.10 & 0.9185 \\
\hline$w+7$ & -0016214 & 0.01118 & 1.45 & 0.1530 \\
\hline U04 & -0.070695 & 0.01156 & 6.12 & 0.0001 \\
\hline U14 & -0.010984 & 001223 & 090 & 0.3730 \\
\hline W14 & -0.070924 & 000896 & 791 & 0.0001 \\
\hline Uo8 & 0.123303 & 000850 & 1.45 & 0.1530 \\
\hline U18: & 0.024230 & 001013 & 239 & 0.0204 \\
\hline W18 & 0.020177 & 001199 & 1.68 & 0.0982 \\
\hline
\end{tabular}

$N=62$

Objective $=23732$

Oblective $\mathrm{N}=147 / 362$

The dynamic utility model features interaction among the asset chotces over time. This characm teristic distinguishes the dynamic utility system from the time series approach. For this model the results are not quite as satisfactory as those just given. They follow in Table 2 . Here, the $R$ squares are slightly lower, the objective* $\mathrm{N}$ statis tic is higher, and there are fewer significant parameters. The static Fourier is nested within the dynamic utility function in ferms of the multi-indexes (see section four). Consequently, we analyze the reduction in the residuals due to the dynamic specification (see Gallant, 1981).
The residual sum of squares from the dynamic model is less than half the size of those obtained from the static model.

Quite often, the methods discussed to this point would be applied to systems of demand equations, as they are here. While the estimated structural equations themselves might be of interest, and for the dynamic versions presented here they could be used to generate forecasts, a typical concern is the elasticity of substitution among the assets. What the fourier provides in this connection is precise estimates of a set of 
own- and cross-elasticities of substitution (and income) at each data point. This can reveal the nature of the substitutability or complementarin ty among the assets and the time-series behavior of this concept.

While we do not wish to explore the fine points of the data set just examined, a further illustration, because it reveals an important characteristic of the dynamic models, is in order. For the more interactive dynamic utility function model, Table 3 presents the estimates of the Allen partial elasticities of substitution among the four commodity bundles studied here. In the table, $E i j$ is the elasticity of substitution between $A i$ and $A j$. The Fourier Flexible Form provides a global approximation and hence we can calculate the asymptotic standard errors for each elasticity (Eij) at each point in time and then evaluate the significance of the estimate. The $T i j$ in the table are the corresponding $t$. statistics for $E i j$.

Неге, we show a complete set of substitution elasticities along with their associated $t$-values. Note that a positive value for the elasticity indicates substitution, while a negative indicates a complementary relation.

Several things stand out in Table 3. Most importantly, the elasticity of substitution between cash and savings assets ( $E 12$ in the table) and between cash and time deposits (E13) are very precisely estimated at all data points. This was not the case for static estimates published elsewhere (Fisher, 1992). While we cannot say a priori what value of the elasticity of substitution is high, an elasticity over unity, as most are in the first column of the table, could be termed "elastic." Note that the result here is that cash and savings accounts are substitutes, as many would expect on the basis of intuition.

More provocatively, however, cash and time deposits appear to be "elastic" complements. This spells trouble for a simple-sum M3 definition of money, if these results are correct, since the simple-sum approach to aggregation treats all components as (perfect) substitutes. Clearly, we are not in a position to doubt our results. We have adopted a rigorous aggregation-theoretic approach and tied the empirical work to that as closely as our data would permit. In fact, the very theory we are using can be invoked in our defense: Economic theory does not say whether commodities will be substitutes or complements in practice. That is, in practice, economic agents decide what assets are substitutes and what are complements. Our results indicate that they use cash and time deposits as if they are complements, at least over this data sample. We also should point out that this is not an unusual finding in this literature (see the survey in Barnett, Fisher and Serletis, 1992).

Another interesting finding, and one that demonstrates the power of the dynamic approach, is that the elasticities shown in Table 3 are much more stable than those obtained from the static model. For this comparison, we refer to the elasticities produced in the static Fourier from the same data set, as published in Fisher (1992). In Figure 1 we show the results for the substitution relation between cash and savings deposits. Note especially that the two series are scaled differently, an adjustment necessary because the static estimates fluctuate so wildly. While both series are generally positive (indicat. ing that they are substitutes), the static estimates are occasionally negative (although they were not significantly less than zero). This sort of result is not ruled out by economic theory, but is still hard to explain in terms of the known characteristics of these assets.

In Figure 2 we present a comparison between the results for the static Fourier and the dynamic utility model where the former results are, again, drawn from the earlier study. In this case we compare cash $(A 1)$ and small time deposits (A3), a relation that is consistently that of complementarity in Table 3.

Once again the dynamic elasticities are relatively constant. In addition, the static elasticities are sometimes positive and sometimes negative (and statistically so, in both cases, at some dates). Clearly, then, the complementary relationship between cash and small time deposits is clearly established in the dynamic utility function results. We note that such results are quite common in this literature (see Barnett, Fisher and Serletis, 1992).

\section{BNy}

In the introduction to this paper; we listed five areas in which existing studies of expenditure systems frequently fall short, in Diewert's opin" ion. Obviously, the innovation of this paper is to convert a static system into a dynamic one; this deals with one of his concerns. Diewert is also concerned that existing studies do not link the theory to the application firmly enough. This we have attempted to address both by setting out 
Table 3

Substitution Elasticities: Dynamic Utility Model $\begin{array}{llllllll}E 12 & T 12 & E 13 & T / 3 & \text { E14 } & T 14 & \text { E23 }\end{array}$

123

0.509

70.2

$70.3 \quad 1291$

$70: 4$ 1255

$71,1,1,167$

$712 \quad 1.163$

$714 \quad 1.115$

$72: 1$

$72: 2 \quad 107$

$72.3 \quad 1.052$

$724 \quad 1010$

$7311 \quad 1033$

$73.3 \quad 1.041$

$73: 4 \quad 1008$

$74: 1 \quad 0920$

$\begin{array}{ll}74: 2 & 1152 \\ 74: 3 & 1.28\end{array}$

$74: 4184$

$75: 1 \quad 1.231$

$75: 2 \quad 1.216$

$75: 3 \quad 1.199$

$75: 4 \quad 1.190$

$\begin{array}{ll}76: 1 & 1.169 \\ 76: 2 & 1.137\end{array}$

$76: 3 \quad 1.107$

$76: 4 \quad 1.055$

$77: 1 \quad 1.041$

$77.2 \cdot 1.030$

$\begin{array}{ll}77.3 & 0.997 \\ 77.4 & 0.977\end{array}$

$78: 1 \quad 1.003$

$78: 2 \quad 1.031$

$78: 3 \quad 0.982$

78:4. $\quad 0.994$

$79: 1 \quad 0.992$

$79: 2 \quad 1.000$

$79: 3 \quad 1.067$

$\begin{array}{ll}79: 4 & 1.139 \\ 80: 1 & 1.194\end{array}$

$80: 2 \quad 1.299$

$\begin{array}{ll}80: 3 & 1.267 \\ 80: 4 & 1.265\end{array}$

$81: 1 \quad 1.296$

$81: 2 \quad 1.323$

$81,3 \quad 1,382$

$81: 4, \quad 1.329$

$82: 1: 1319$

$82+3 \quad 1.395$

$82,4 \quad 1349$

$83+\square 1460$

$83 . \quad 1,479 \quad 335$

$833 \quad 1485 \quad 3344$

$83.4 \quad 1,483 \quad 3,396$

$841 \quad 1483 \quad 3421$

$84.2 \quad 1493 \quad 3.24$

$843 \quad 1465 \quad 3392$

$844 \quad 1,470 \quad 3640$

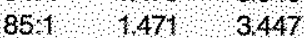

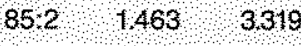

$-0,250 \quad 2367$

$3163 \quad 0.259 \quad 2532$

$3389 \quad-0270 \quad 2751$

$3.669 \quad-0.272 \quad 3.026$

$3896 \quad-0.270 \quad 3.071$

$4050 \quad 0.279 \quad 3368$

$3896-0.265 \quad 3.202$

4.083

$-0.266 \quad 3.382$

$-0.273 \quad 3.596$

$0.273 \quad 3.590$
$-0.282 \quad 3873$

$4.524 \quad-0.297 \quad 4.058$

$4.672-0.335$

4.543

0.446

5.808

4.726

$-0465$

-0.507
-0.426

5.954

5954
5.233

$-0.364$

4063

4.615

4.094
3.977

$-0.392$

4663

$-0.281$

3.543

$-0.294$

3.352
3.577
3.539

3.577
3.539

$-0.287$

3.539

$-0.286$

3.713

$-0.291$

3.880

$-0.303$

4.207

4.157

$-0.295$

4.235

$-0.318 \quad 4.586$

$-0.330$

4.813

$-0.323$

4.654

$-0.420$

$-0.527$

5.550

6.350

$-0.569$

$-0.576$

6.378

6.336

$-0.545$

6.507

6.911

$-0.634$

6.714

$-0.503$

$-0.472$

5.621
5.429

$-0.590 \quad 6.200$

$-0.586 \quad 5.700$

$-0.552$

5.332

\begin{tabular}{ll}
$-0.581 \quad 4.869$ \\
\hline
\end{tabular}

$-0.573$

5.281

$-0.562$

5401

-0.532
-0.435

5.211

$-0.380$

4.379

4034

$-0323 \quad 2887$

$-0328$

2730

$-0341$

$-0342$

2768

2826

$-0347$

2874

2581

$-0388$

3119

$-0376$

3254

$-0,306$
$0445 \quad 1394 \quad-0.614$

$\begin{array}{rrr}037 & 1,218 & -0601 \\ & -0592\end{array}$

0.290

0273

0.233

0.195

0.236

$0+188$

0.134

0.065

0.046

$-0.047$

$-0.150$

$-0.94$

$-0.302$

$-0.074$

0.090

$-0.010$

0.169

0.204

0.162

0.168

0.165

0.136

0.107

0.049

0.056

0.041

$-0.020$

$-0.054$

$-0.022$

$-0.008$

$-0.159$

$-0.274$

$-0.329$

$-0.335$

$-0.260$

$-0.319$

$-0.289$

$-0.074$

$-0.067$

$-0.164$

$-0.110$

$-0.040$

$-0.024$

$-0.052$

$-0.054$

$-0.011$

0.102

0.117

0358

0.410

0401

0.385

0373

0.438

0,318

0287

0,379

0429

1,107

1.057

$0.932-0.095$

0.832

$-0,602$

$0.825 \quad-0.619$

0.623

0.328

0.230
0.261

0.875

2.083

0.386
0.375

0.049

0.669
0.790

0.790
0.659

0.685

0.683

0.588

0.240

0.273

0.206

0.109

0.118

0.044

0.944

1.722

2.097

2.119

1.529

1.806
1.456

0.332

0.313

0.707

0.409
0.140

0.071

0.172

0.191

0.362

0.443

0951

0.996

0953
0940

0.917

0978

078

0.971
1,067

$-0.605$

$-0.582$

$-0.568$

$-0.527$

$-0.421$

$-0.412$

$-0.381$

-0.419
-0.444

$-0.460$

$-0.548$

$-0.579$

$-0.567$

$-0.576$

$-0.587$

$-0.588$

$-0.586$

$-0.576$

$-0.586$

$-0.581$

$-0.555$

$-0.539$

$-0.549$

$-0.546$

$-0.463$

$-0.357$

$-0.319$

$-0.313$

$-0.335$

$-0.237$

$-0.212$

$-0.301$ 
Figure 1

Substitution Elasticities Between Cash (A1) and

Savings Deposits (A2), 1970-1985

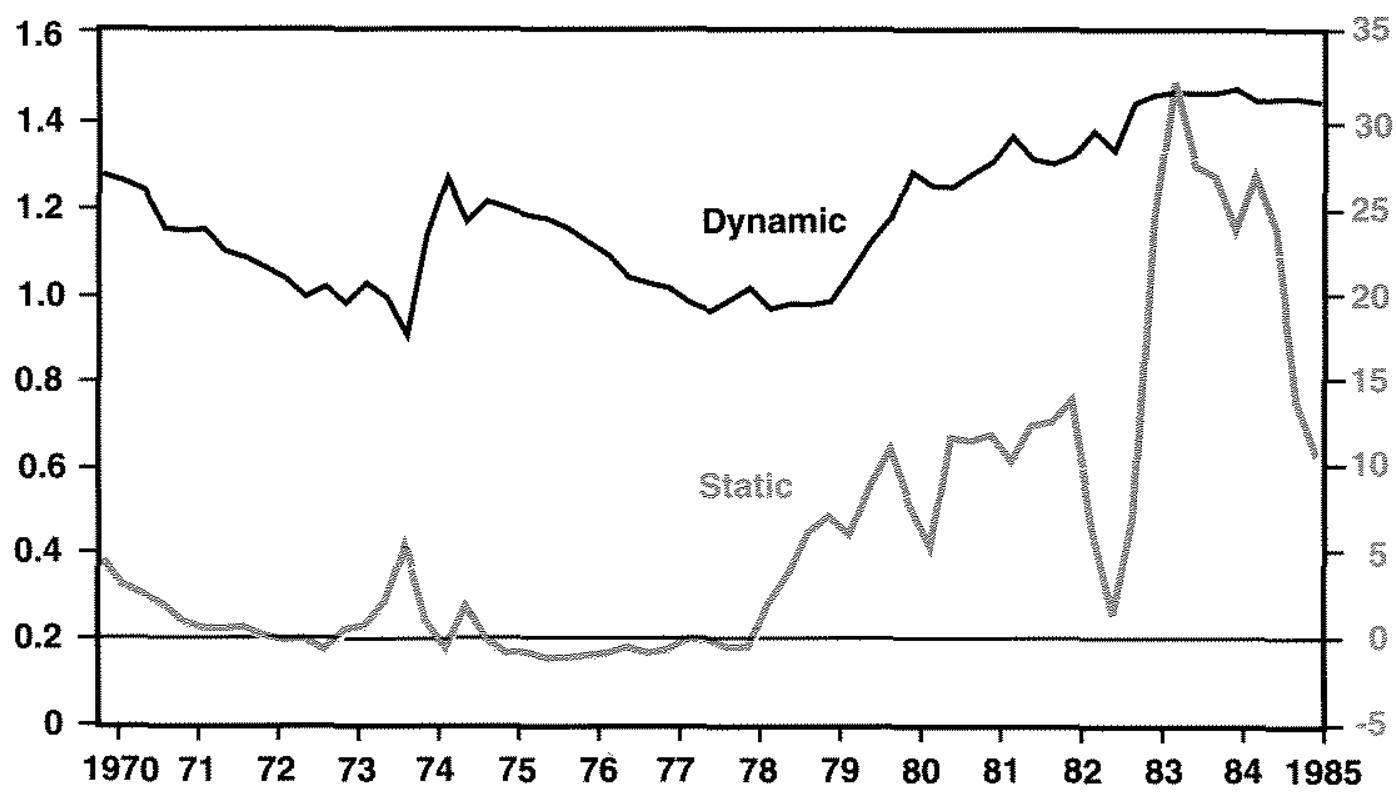

Figure 2

Substitution Elasticities Between Cash (A1) and

Time Deposits (A3), 1970-1985

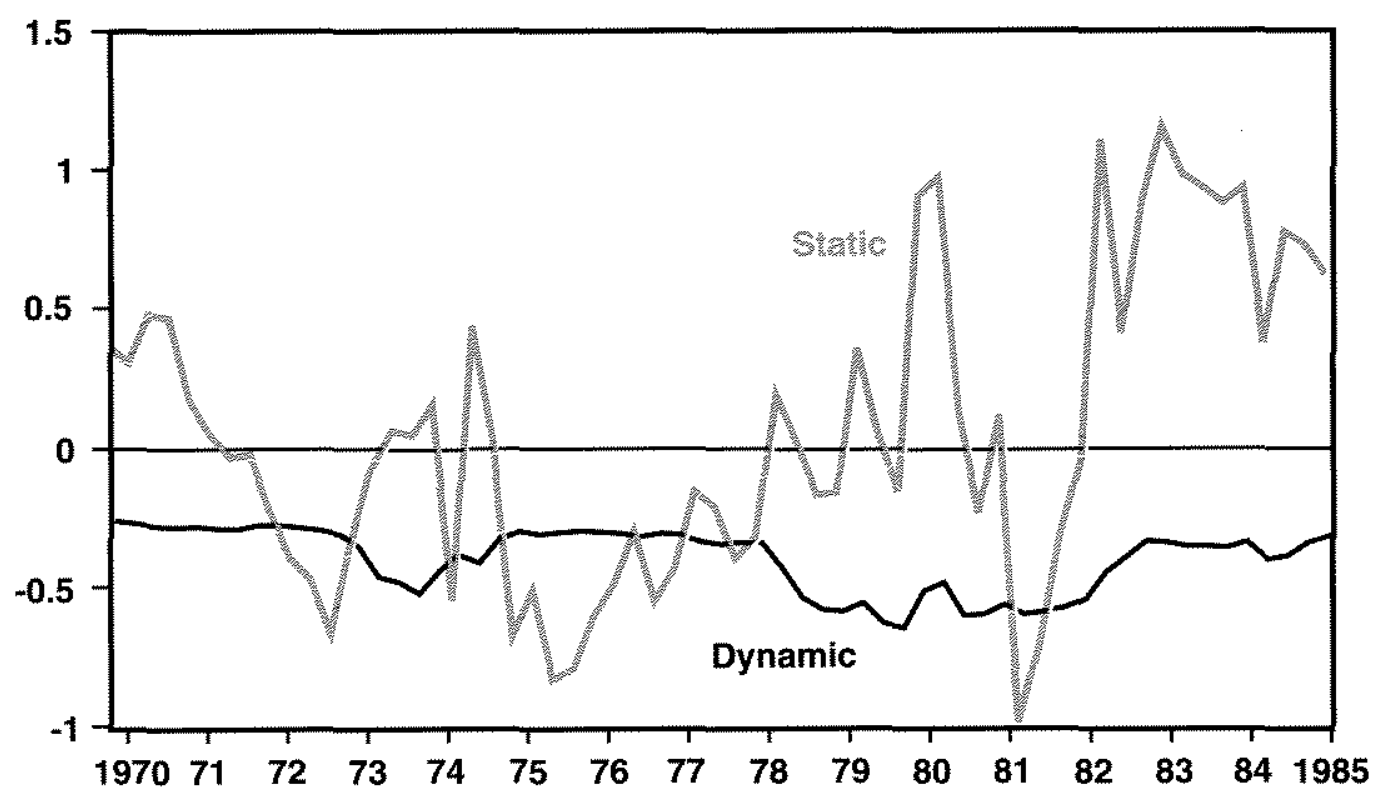


the theory and by dealing with two of his further concerns: aggregating in a consistent fashion and employing a system that provides arbitrarily accurate estimates of the partial derivatives of the system. What we did not do, which is in his list of concerns, is examine the model at every data point.

In our results, the dynamic models derived and estimated appear clearly superior to the (nested) static models. We are not able to compare the two dynamic formulations directly, because they are not nested, but we find the statistical performance of the time series approach to be superior, while the dynamic-utility approach seems better able to capture the economic interactions among the assets studied. Furthermore, most of the estimated share equations produced white noise residuals, and this is a characteristic that is not shared by the static estimates, whether of the nested form in this paper or in the earlier (static) Fourier results that we have been using as a benchmark.

For the dynamic utility model, we have produced a set of elasticities of substitution and charted those between cash (M1 + OCD) and savings deposits and between cash and small time deposits. The former are shown to be substitutes in the dynamic system, and, more important, to be much more stable than static estimates produced in an earlier study. The latter are actually complements, although the negative elasticity of substitution is generally less than minus one, a finding that is not without foundation theoretically. We anticipate that further study of the model and/or the U.S. data will provide further observations on this phenomenon.

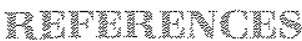

Anderson, G. J. "The Structure of Simultaneous Equations Estimation: A Comment," Journal of Econometrics (October 1980), pp. $271-76$.

and R. W. Blundel. "Estimation and Hypothesis

Testing in Dynamic Singular Equation Systems," Econometrica (November 1982), pp. 1559-72.

"Testing Restrictions in a Flexible Demand System: An Application to Consumers' Expenditure in Canada." Review of Economic Studies (July 1983), pp. 397-410.
Barnet, William A. "The User Cost of Money" Economics Letters (vol. 1, no. 2, 1978), pp. 145-49.

Douglas Fisher, and Apostolos Sertetis. "Consumer Theory and the Demand for Money," Journal of Economic Literature (December 1992), pp. 2086-119.

Deaton, Angus, and John Muellbauer. Economics and Consumer Behaviour. Cambridge University Press, 1980.

Diewert, W. E. "Applications of Dually Theory;" in M.D. Intrilligator and D.A. Hendricks, Frontiers of Quantitative Economics. North-Holland, 1974, pp. 106-206.

Ewis, Nabil A., and Douglas Fisher. "Toward a Consistent Estimate of the Substitutability between Money and Near Monies," Journal of Macroeconomics (spring 1985), pp. $151-74$.

Farr, Helen, and Deborah Johnson. "Revisions in the Monetary Services (Divisia) Indexes of Monetary Aggregates," Special Studies Paper no. 189. Board of Governors of the Federal Reserve System, $1985 a$.

, and "Revisions in the Monetary Services (Divisia) Indexes of the Monetary Aggregates," Staff Study no. 147. Board of Governors of the Federal Reserve System, 1985b.

Fisher, Douglas. Money Demand and Monetary Policy. University of Michigan Press, 1989.

"Money-Demand Variability: A Demand-Systems Approach," Joumal of Business \& Economic Statistics (April 1992), pp. $143-51$.

Gallant, A. Ronald. "On the Bias in Flexible Functional Forms and an Essentially Unbiased Form: The Fourier Flexible Form:" Journal of Econometrics (February 1981), pp. $211-45$.

and Dale W. Jorgenson. "Statistical Inference for a System of Simultaneous, Nonlinear, Implicit Equations in the Context of Instrumental Variable Estimation," Journal of Econometrics (October/December 1979), pp. 275-302.

Pollak, Robert A., and Terence J. Wales. Demand System Specification and Estimation. Oxford University Press, 1992.

Serletis, Apostolos. "The Demand for Divisia Money in the United States: A Dynamic Flexible Demand System," Journal of Money, Gredit and Banking (February 1991), pp. 35-52.

Swofford, James L., and Gerald A. Whitney. "Nonparametric Tests of Utility Maximization and Weak Separability for Consumption, Leisure, and Money," Review of Economics and Statistics (August 1987), pp. 458-64.

and "A Comparison of Nonparametric Tests of Weak Separability for Annual and Quarterly Data on Consumption, Leisure, and Money," Journal of Business and Economics Statistics (April 1988), pp. 241-46.

Varian, Hal R. "The Nonparametric Approach to Demand Analysis," Econometrica (July 1982), pp. 945-73.

"Nonparametric Tests of Consumer Behaviour;", Review of Economic Studies (January 1983), pp. 99-110. 